\title{
Maternally Administered Dexamethasone at 0.7 of Gestation Suppresses Maternal and Fetal Pituitary and Adrenal Responses to Hypoxemia in Sheep
}

\author{
MICHELLE A. KUTZLER, TURHAN COKSAYGAN, A. DAMON FERGUSON, \\ STELLA E. VINCENT, AND PETER W. NATHANIELSZ
}

\author{
Department of Clinical Sciences [M.A.K.], Oregon State University, Corvallis, OR 97331, U.S.A.; \\ Departments of Biomedical Sciences [T.C.], Microbiology \& Immunology [A.D.F.], and Population Medicine \\ \& Diagnostic Services [S.E.V.], Cornell University, Ithaca, NY 14853, U.S.A.; and Department of Obstetrics \\ and Gynecology [P.W.N.], New York University School of Medicine, New York, NY 10016, U.S.A.
}

\begin{abstract}
Women who are at risk of preterm delivery are treated with antenatal steroids to facilitate fetal lung maturation. During this period, there is a potential for fetal or maternal hypoxemia to occur. Fetal responses to hypoxemia in sheep are well documented. However, less is known regarding maternal responses to hypoxemia. Therefore, we determined the effects of dexamethasone $(\mathrm{DM})$ on maternal and fetal responses to hypoxemia in sheep. Ewes received four i.m. injections of DM or saline at 12-h intervals beginning at $103 \mathrm{~d}$ of gestation. Samples for ACTH, cortisol, and glucose were collected at $0900 \mathrm{~h}$. At $105 \mathrm{~d}$ of gestation, hypoxemia was induced for $1 \mathrm{~h}$ by maternal nitrogen gas inhalation. Samples for ACTH, cortisol, and glucose were collected at 15-min intervals before, during, and after the hypoxemia challenge. Fluorescent microspheres were administered to the mother and the fetus before and during hypoxemia to measure organ perfusion. DM suppressed basal fetal and maternal cortisol and ACTH concentrations but increased glucose levels. DM also increased fetal but not maternal blood pressure. In control subjects, hypoxemia elevated fetal and maternal cortisol
\end{abstract}

\section{ABSTRACT}

and ACTH concentrations. These responses were obliterated by DM. Hypoxemia increased blood pressure in DM-exposed fetuses but not in control subjects. In addition, hypoxemia decreased fetal adrenal vascular resistance in saline but not DM fetuses or ewes from either treatment group. In summary, maternal administration of a low dose of DM at 0.7 of gestation suppresses maternal and fetal adrenal function and changes fetal responses to hypoxemic stress to resemble those observed later in gestation. (Pediatr Res 55: 755-763, 2004)

Abbreviations
dGA, days of gestation
DM, dexamethasone
HR, heart rate
$\mathrm{O}_{\mathbf{2}}$ sat, arterial oxygen saturation of hemoglobin
$\mathbf{P a O}_{2}$, arterial pressure of oxygen
PaCO $_{2}$, arterial pressure of carbon dioxide

Administration of synthetic glucocorticoids, such as betamethasone and dexamethasone (DM), to accelerate fetal lung maturation has become a routine treatment for women who are at risk of preterm labor $(1,2)$. This treatment is designed to elevate fetal plasma glucocorticoid levels, mimicking the maturational effects that normally occur close to term in humans and other species produced by the endogenous prepartum increases in fetal plasma cortisol (3-6). Prophylactic antenatal

Received December 3, 2002; accepted August 26, 2003.

Correspondence: Michelle Kutzler, DVM, PhD, DACT, Oregon State University, College of Veterinary Medicine, Department of Clinical Sciences, 158 Magruder Hall, Corvallis, OR 97331, U.S.A.; e-mail: michelle.kutzler@oregonstate.edu

This investigation was supported by the National Institutes of Health from the National Heart, Lung and Blood Institute; National Research Service Award (F32 HL68393); and R01 HL055416 and P01 HD21350.

DOI: 10.1203/01.PDR.0000117847.59343.B2 glucocorticoid treatment has resulted in a significant decrease in preterm infant morbidity and mortality $(1,7-12)$.

Despite the clear benefits of antenatal maternal glucocorticoid therapy, unwanted effects on organ systems other than the lung have been identified in both clinical human and research animal studies. For instance, exogenous glucocorticoid use has been associated with reduced weight and head circumference in infants at birth $(7,13,14)$. In addition to the effects on fetal growth, antenatal glucocorticoid treatment administered to fetal sheep in the last third of gestation increases fetal blood pressure (BP) (15-19). Repeated maternal betamethasone administration in sheep also suppresses neuroendocrine and adrenal responsiveness in the preterm newborn lamb $(20,21)$.

Responses to acute hypoxemia in fetal sheep $>120 \mathrm{~d}$ of gestation (dGA) are well established (22-25). Acute fetal hypoxemia evokes orchestrated cardiovascular, metabolic, and 
endocrine responses that aid in fetal survival during periods of reduced $\mathrm{O}_{2}$ availability. However, relatively little is known about fetal responses to acute hypoxemia before $120 \mathrm{dGA}$. Cardiovascular responses of fetal sheep to hypoxemia before $100 \mathrm{dGA}$ are different from those of fetal sheep at $>100 \mathrm{dGA}$ $(26,27)$. In addition, gestational changes in organ blood flow (28) and neurohormonal regulation (29) suggest that the responses to acute hypoxemia in fetuses $<120 \mathrm{dGA}$ would be different from those $>120$ dGA.

Studies investigating the effects of glucocorticoids on the capacity of the fetus ( $>120 \mathrm{dGA})$ to respond to hypoxemia have shown that treatment of fetal sheep either with cortisol administered i.v. for $5 \mathrm{~h} \mathrm{(30)}$ or for $48 \mathrm{~h}$ (31) or with DM administered by an implant ( $700 \mu \mathrm{g})$ adjacent to the paraventricular nucleus (32) suppresses pituitary and adrenal responses to acute hypoxemia. However, the effect of maternal antenatal DM administration on the fetal responses to acute hypoxemia at $<120 \mathrm{dGA}$ is unknown. Similarly, there is no information on the effects of DM administration to the pregnant ewe on maternal endocrine and cardiovascular responses to acute hypoxemia.

We hypothesized that a single 48 -h course of DM at 0.7 of gestation would suppress maternal and fetal adrenal responses and accelerate the normal cardiovascular responses to a $1-\mathrm{h}$ episode of hypoxemia. We chose this gestational age because it corresponds to the stage of fetal development at which prophylactic therapy is given to women in premature labor. We focused our studies on the metabolic, neuroendocrine, and organ perfusion responses to DM.

\section{METHODS}

Care of animals. A total of 10 Rambouillet ewes $(60-70 \mathrm{~kg})$ carrying singleton fetuses of known gestational age were studied. Ewes were housed in individual metabolic cages and had free-access to pelleted feed and water. Ewes were maintained on a 14-h light/10-h dark cycle. All experimental procedures were approved by the Cornell University Institutional Animal Care and Use Committee, and the facilities were approved by the Association for Assessment and Accreditation of Laboratory Animal Care.

Surgical procedures. Surgery was performed at $96 \pm 1 \mathrm{dGA}$ (term $149 \mathrm{dGA}$ ). Ewes were premedicated with $1 \mathrm{mg}$ of glycopyrrolate (Robinul-V (R), Fort Dodge Animal Health, Overland Park, KS, U.S.A.) i.m. and given $1 \mathrm{~g}$ of ampicillin (Polyflex, Ayerst Veterinary Laboratories, Guelph, Ontario, Canada) i.m. After administration of $1 \mathrm{~g}$ of ketamine (Ketaflo; Abbott Laboratories, North Chicago, IL, U.S.A.) i.m., anesthesia was induced with 4\% isoflurane gas (Isoflo; Abbott Laboratories) administered with a face mask. Ewes were intubated, and anesthesia was maintained with $1.5-2.0 \%$ isoflurane and $\mathrm{O}_{2}$ with a flow rate of 2-3 L/min via positive-pressure ventilation. The right side and ventral midline of the ewe's neck as well as her ventral abdomen from xiphoid to pubis were shaved and prepared aseptically for surgery.

Each ewe was instrumented with left ventricular, carotid, and femoral artery; jugular and femoral vein; and tracheal catheters. The left ventricular and carotid artery catheters both were placed within the right carotid artery. Exact placement of the ventricular catheter was confirmed using a pressure transducer (Disposable BP Transducer, model no. MLT 0670; PowerLab AD Instruments, Colorado Springs, CO, U.S.A.) and data acquisition software (WINDAQ, DATAQ Instruments). The femoral artery and vein catheters were advanced until their tips were in the descending aorta or inferior vena cava, respectively. All catheters were prefilled with heparinized saline $(20 \mathrm{IU} / \mathrm{mL})$.

The gravid uterus was exposed through a ventral midline abdominal incision. The fetal neck was exteriorized through a uterine incision, and a jugular vein and carotid artery catheter were placed. An additional catheter was secured to the skin of the fetal neck for monitoring intra-amniotic pressure. The fetus was returned to the uterus, and the uterine incision was closed. Next, a fetal hind limb was exteriorized through a second uterine incision. A catheter was inserted into the fetal descending aorta via the femoral artery, and another catheter was inserted into the fetal inferior vena cava via the pedal vein. The second uterine incision was closed, and all catheters were exteriorized through the flank of the ewe. Teflon-coated stainless steel wire electrodes were sewn into the myometrium to permit continuous monitoring of uterine electromyographic activity, and the abdominal incision was closed in layers.

Postoperative care. Ampicillin (500 mg, Amp-Equine; Pfizer Animal Health, Philadelphia, PA, U.S.A.) was administered postoperatively twice daily for $5 \mathrm{~d}$ to the ewe and the fetus via the jugular and amniotic catheters, respectively. The ewes also received $3 \mathrm{~d}$ of oral phenylbutazone $(0.5-1.0 \mathrm{~g}$, Phenylzone paste; Schering-Plough, Kenilworth, NJ, U.S.A.) daily for postoperative analgesia. Vascular catheters were maintained patent by a continuous infusion of heparinized saline $(20 \mathrm{IU} / \mathrm{mL})$ at $0.5 \mathrm{~mL} / \mathrm{h}$. Animals were allowed at least $4 \mathrm{~d}$ to recover from surgery before baseline measurements were taken.

Experimental procedures. Ewes received four i.m. injections of either $2 \mathrm{mg}$ of DM (Azium, Schering; $n=6$ ) or saline $(n=4)$ at $12-\mathrm{h}$ intervals beginning at $103 \mathrm{dGA}(\sim 30 \mu \mathrm{g} / \mathrm{kg}$ $\mathrm{DM}$, weight-adjusted dose). At $105 \mathrm{dGA}$ and $47 \mathrm{~h}$ after the onset of treatment, fetal hypoxemia was induced by maternal nitrogen gas inhalation in both treatment groups as previously described (33) to reduce fetal arterial pressure of oxygen $\left(\mathrm{PaO}_{2}\right)$ by $\sim 40 \%$ of baseline values. After $1 \mathrm{~h}$, nitrogen gas delivery was discontinued and the ewe was allowed to breathe room air for an additional $15 \mathrm{~min}$. Ewes were then killed by an overdose $(15 \mathrm{~mL})$ of pentobarbital sodium (Fatal Plus; Vortech Pharmaceuticals, Dearborn, MI, U.S.A.). The positioning of catheters was confirmed at necropsy.

Paired maternal and fetal carotid artery samples were taken daily during a period of minimal uterine electromyographic activity for the analysis of arterial blood gases and measurement of blood glucose and plasma hormone concentrations. Samples were taken at $0900 \mathrm{~h}$ on the day before the treatment began (T-1) and on the $2 \mathrm{~d}$ during treatment (T1 and T2), as well as 30 and $15 \mathrm{~min}$ before, during (15 and $45 \mathrm{~min}$ after the onset of hypoxemia), and 15 min after the period of hypoxemia. Plasma samples for hormone measurements were stored at $-70^{\circ} \mathrm{C}$ until analyzed. Additional fetal carotid arterial blood 
gas samples were taken at 5-min intervals until 20 min into the hypoxemia challenge to confirm that fetal $\mathrm{PaO}_{2}$ was within the targeted range. The volume of fetal blood removed for each sample $(5 \mathrm{~mL})$ was replaced with an equal volume from an age-matched donor animal.

Blood gas measurements. Fetal and maternal $\mathrm{PaO}_{2}$, arterial pressure of carbon dioxide $\left(\mathrm{PaCO}_{2}\right), \mathrm{pH}$, and glucose were measured with a blood gas analyzer (ABL 500; Radiometer Medical A/S, Copenhagen, Denmark) with measurements corrected to core body temperature $\left(39^{\circ} \mathrm{C}\right)$. Arterial oxygen saturation of $\mathrm{Hb}\left(\mathrm{O}_{2}\right.$ sat $)$ and $\mathrm{Hb}$ concentration were measured with a hemoximeter (OSM 2; Radiometer Medical A/S).

Hemodynamic measurements. Fetal and maternal aortic $\mathrm{BP}$, inferior vena cava pressure, heart rate (HR), and amniotic pressure were recorded continuously with pressure transducers (Disposable BP Transducer, model no. MLT 0670; PowerLab AD Instruments). Maternal and fetal mean arterial blood pressure were corrected for central venous pressure. In addition, fetal mean arterial BP was corrected for intra-amniotic pressure. Pressure, HR, and electromyographic signals were digitized with a data acquisition program (WinDAQ, DATAQ Instruments, Akron, OH, U.S.A.).

Hormone analysis. Maternal and fetal plasma ACTH concentrations were measured using a solid-phase, two-site chemiluminescence enzyme immunometric assay (DPC Immulite assay; Diagnostic Products Co., Los Angeles, CA, U.S.A.) on an automated immunoassay analyzer (IMMULITE; Diagnostic Products Co.). In addition to ACTH 1-39, cross-reactivity was detected only with ACTH (18-39) at 13 and $15 \%$ for 500 and $5000 \mathrm{pg} / \mathrm{mL}$ added. The sensitivity of the assay (defined as the concentration $2 \mathrm{SD}$ above zero) was $9 \mathrm{pg} / \mathrm{mL}$ plasma. For samples measuring 20 and $200 \mathrm{pg} / \mathrm{mL}$, the intra-assay coefficients of variation were 4.75 and $3.54 \%$, respectively. For samples measuring 50 and $150 \mathrm{pg} / \mathrm{mL}$, the interassay coefficients of variation were 12.01 and $16.46 \%$, respectively. Values are expressed as $\mathrm{pg} / \mathrm{mL}$.

Maternal and fetal plasma cortisol concentrations were measured using a modified (standard curve from $2.5-500 \mathrm{ng} / \mathrm{mL}$, sample volume $=50 \mu \mathrm{L}$ ) DPC Coat-A-Count RIA kit (Diagnostic Products $\mathrm{Co}$.). The cross-reactivity with prednisone and prednisolone was 7.6 and $2.3 \%$, respectively. The crossreactivity of 11 -deoxycortisol was $11.4 \%$. Cross-reactivities to other steroids were $<1 \%$. The sensitivity of the assay (defined by $90 \%$ bound/free) was $2 \mathrm{ng} / \mathrm{mL}$ plasma. For plasma pools measuring 28 and $144 \mathrm{ng} / \mathrm{mL}$, the interassay coefficients of variation were 8.66 and $8.03 \%$ and the intra-assay coefficients of variation were 4.14 and $3.2 \%$, respectively. Values are expressed as $\mathrm{ng} / \mathrm{mL}$.

Measurement of regional organ flows. Ten minutes before the induction of hypoxemia, 4 million fluorescent microspheres (15 $\mu \mathrm{m}$; Molecular Probes, Eugene, OR, U.S.A.) were injected into the maternal left ventricular catheter as well as the fetal femoral and jugular vein catheters ( 2 million microspheres per fetal catheter) as previously described (34). Reference blood samples for measuring blood flow were collected simultaneously from the maternal femoral artery and fetal femoral and carotid arteries at a constant rate of $3.88 \mathrm{~mL} / \mathrm{min}$. Fluorescent microspheres were again administered $10 \mathrm{~min}$ before the end of hypoxemia. For each microsphere injection, a fluorescent color with a distinct excitation and emission wavelength was used. This method for measuring blood flow was previously validated in our laboratory (34).

Fetal and maternal tissues were collected at necropsy for microsphere retrieval. From the fetus, the whole adrenal glands (adrenal) and a 1- to 2-g biopsy from left ventricle (cardiac), left frontal cortex (cortical), left femoral muscle, and left renal cortex (renal) were individually weighed and placed in a glass test tube. From the ewe, a 1- to 2-g biopsy taken from the left adrenal cortex, left adrenal medulla, left femoral muscle, and left renal cortex (renal) was sampled. Briefly, tissues were digested with potassium hydroxide, and the liberated fluorescent microspheres were separated by filtration from the tissue hydrolysate. The fluorescent dyes from the microspheres were then extracted with a solvent (2-ethoxyethyl acetate; Cellusolve, Aldrich Chemical Co. Inc., Milwaukee, WI, U.S.A.). The fluorescence of the dye-containing solution was quantified in a fluorometer (Fluoromax-II Instruments S. A. Inc., Edison, NJ, U.S.A.).

Data analysis. During the baseline and treatment days, mean maternal and fetal arterial BP and HR were calculated at hourly intervals for $72 \mathrm{~h}$. During the hypoxemia challenge, mean maternal and fetal arterial BP and HR were calculated at 15-min intervals from $30 \mathrm{~min}$ before the onset of hypoxemia until $15 \mathrm{~min}$ after the end of hypoxemia. Blood gas, glucose, $\mathrm{ACTH}$, cortisol, and BP data collected at 30 and $15 \mathrm{~min}$ before onset of hypoxemia, 15 and $45 \mathrm{~min}$ after onset of hypoxemia, and $15 \mathrm{~min}$ after the end of hypoxemia were averaged and reported as Pre-HX, HX, and Post-HX, respectively. Incremental increases in glucose concentrations were determined with respect to prehypoxemia baseline values for each individual and then calculating the mean for the group. Fetal organ perfusion pressure was calculated as the difference between the mean arterial BP and the venous pressure after correction for intra-amniotic pressure. Maternal organ perfusion pressure was calculated as the difference between the mean arterial BP and the venous pressure. Basal (Pre-HX) and hypoxemia (HX) organ blood flow $\left(\mathrm{ml} \cdot \min ^{-1} \cdot 100 \mathrm{~g}\right.$ tissue $\left.{ }^{-1}\right)$ was determined $10 \mathrm{~min}$ before and $50 \mathrm{~min}$ after the onset of hypoxemia, respectively. Maternal and fetal organ vascular resistances $\left(\mathrm{mm} \mathrm{Hg} \cdot \mathrm{ml}^{-1} \cdot \mathrm{min} \cdot 100 \mathrm{~g}\right.$ tissue $\left.{ }^{-1}\right)$ were calculated as the quotient of organ perfusion pressure divided by mean organ blood flow. Values are expressed as mean \pm SEM unless otherwise stated. Changes in variables within and between treatment groups were assessed using a one-way ANOVA with Tukey's post hoc test. Statistical significance was accepted at $p<0.05$.

\section{RESULTS}

Arterial blood gas, acid-base, and metabolite status. In the control animals, all fetal and maternal blood gas parameters and plasma glucose concentrations were within the normal range and did not change during the treatment period (Table 1). DM treatment had no effect on daily blood gas parameters in the fetuses and ewes. However, both fetal and maternal glucose 
Table 1. Effect of DM treatment on blood gas and glucose status

\begin{tabular}{|c|c|c|c|c|c|c|}
\hline \multirow[b]{2}{*}{ Sample } & \multicolumn{6}{|c|}{ Saline } \\
\hline & $\mathrm{T}-1$ & $\mathrm{~T} 1$ & $\mathrm{~T} 2$ & $\mathrm{~T}-1$ & $\mathrm{~T} 1$ & $\mathrm{~T} 2$ \\
\hline $\mathrm{PaO}_{2}(\mathrm{~mm} \mathrm{Hg})$ & $24.7 \pm 1.46$ & $25.6 \pm 0.36$ & $23.2 \pm 1.46$ & $122.2 \pm 7.47$ & $123.8 \pm 7.54$ & $111.8 \pm 8.13$ \\
\hline $\mathrm{PaCO}_{2}(\mathrm{~mm} \mathrm{Hg})$ & $49.6 \pm 1.61$ & $52.3 \pm 1.08$ & $51.6 \pm 1.48$ & $37.3 \pm 1.59$ & $37.8 \pm 1.06$ & $39.6 \pm 1.67$ \\
\hline $\mathrm{O}_{2}$ sat $(\%)$ & $58.2 \pm 5.66$ & $63.7 \pm 6.42$ & $62.3 \pm 3.72$ & $94.3 \pm 2.85$ & $97.7 \pm 0.85$ & $94.5 \pm 0.81$ \\
\hline \multirow[t]{3}{*}{ Glucose $(\mathrm{mmol} / \mathrm{L})$} & $1.1 \pm 0.20$ & $1.1 \pm 0.14$ & $1.0 \pm 0.14$ & $3.5 \pm 0.33$ & $3.4 \pm 0.28$ & $3.7 \pm 0.24$ \\
\hline & \multicolumn{6}{|c|}{ DM } \\
\hline & \multicolumn{3}{|c|}{ Fetal } & \multicolumn{3}{|c|}{ Maternal } \\
\hline Sample & $\mathrm{T}-1$ & $\mathrm{~T} 1$ & $\mathrm{~T} 2$ & $\mathrm{~T}-1$ & $\mathrm{~T} 1$ & $\mathrm{~T} 2$ \\
\hline $\mathrm{Hb}(\mathrm{mg} / \mathrm{dL})$ & $7.9 \pm 0.56$ & $8.9 \pm 0.53$ & $8.7 \pm 0.76$ & $10.1 \pm 0.52$ & $9.5 \pm 0.44$ & $9.1 \pm 0.28$ \\
\hline Hct $(\%)$ & $30.8 \pm 2.03$ & $34.2 \pm 2.64$ & $33.4 \pm 3.55$ & $28.7 \pm 0.91$ & $30.8 \pm 1.88$ & $30.2 \pm 1.73$ \\
\hline Glucose $(\mathrm{mmol} / \mathrm{L})$ & $0.9 \pm 0.08$ & $1.6 \pm 0.19 *$ & $1.5 \pm 0.10^{*}$ & $3.3 \pm 0.14$ & $4.5 \pm 0.31^{*}$ & $4.4 \pm 0.20^{*}$ \\
\hline
\end{tabular}

Hct, hematocrit.

Values are given for baseline (T-1), after the first treatment day (T1), and after the second treatment day (T2) after maternal administration of saline $(n=4)$ or DM $(n=6)$ for $48 \mathrm{~h}$ beginning at $09.0 \mathrm{~h}$ on $103 \mathrm{dGA}$. Mean \pm SEM.

$* p<0.05$ compared with baseline levels and saline-treated group.

concentrations were increased during the 48 -h treatment period compared with baseline levels and the saline-treated groups.

Fetal blood gas parameters and glucose concentrations during the hypoxemia protocol are shown in Table 2. Before the onset of the hypoxemia challenge, values for fetal $\mathrm{pH}, \mathrm{PaO}_{2}$, $\mathrm{PaCO}_{2}, \mathrm{O}_{2}$ sat, $\mathrm{Hb}$ concentration, and hematocrit were not different between saline-infused and DM-treated animals. During hypoxemia, the decreases in fetal $\mathrm{PaO}_{2}$ and $\mathrm{O}_{2}$ sat were similar in both groups. However, during hypoxemia, DMtreated fetal glucose concentrations remained greater than in the saline-treated group.

In fetuses of saline-treated ewes, blood glucose concentrations were elevated during HX compared with Pre-HX values (Table 2). Despite elevated Pre-HX blood glucose concentrations in DM-treated fetuses, hypoxemia further increased glucose levels compared with values from Pre-HX and salinetreated fetuses. At Post-HX, all blood gas parameters returned to Pre-HX levels in both treatment groups except for fetal blood glucose concentrations, which remained elevated Post-HX in the DM-treated group compared with Pre-HX and saline-treated values. The increment in fetal glucose concentration calculated with respect to Pre-HX values was decreased in the DM-treated group compared with the saline group during HX but increased at Post-HX.

Values for maternal carotid arterial blood gas parameters and glucose concentrations during the hypoxemia protocol are shown in Table 2 . These variables were similar in the salinetreated and DM-treated ewes at Pre-HX. Maternal carotid $\mathrm{PaO}_{2}$ and $\mathrm{O}_{2}$ sat fell rapidly to similar values in the saline-treated and DM-treated ewes during the hypoxemia challenge. Other blood gas parameters remained at Pre-HX values during the hypoxemia challenge and were not different between treatment groups. In saline-treated and DM-treated ewes, blood glucose concentrations remained unchanged during the hypoxemia challenge, with glucose levels from DM-treated ewes greater than in saline-treated ewes at all time points.

Hormone concentrations. Baseline plasma cortisol and ACTH concentrations were similar in both groups of fetuses and mothers (Fig. 1). During $48 \mathrm{~h}$ of DM treatment, fetal and maternal cortisol concentrations were decreased compared with baseline and saline-treated values. Similarly, ACTH concentrations from DM-treated fetuses were decreased during the 48-h treatment period compared with baseline and salinetreated values. However, ACTH concentrations from DMtreated mothers were not significantly decreased until the last $24 \mathrm{~h}$ during the treatment period compared with baseline and saline-treated levels.

In saline-treated fetuses and mothers, significant increases in plasma cortisol and ACTH concentrations occurred during hypoxemia when compared with Pre-HX levels (Fig. 2). In the saline-treated fetuses and mothers, plasma cortisol concentrations remained elevated Post-HX, whereas ACTH concentrations remained increased only in comparison with Pre-HX in the mothers. In contrast, no rise in plasma ACTH or cortisol concentrations occurred during acute hypoxemia in the DMtreated fetuses or mothers.

Maternal and fetal blood pressure and regional blood flows. DM administration elevated fetal BP after the first three injections without affecting maternal BP (Fig. 3). Acute hypoxemia did not increase maternal BP in either treatment group, but DM-treated fetal BP was increased (Table 2). The effects of DM treatment and hypoxemia on fetal organ blood flow and vascular resistance are summarized in Figure 4. During normoxia after a 48-h treatment 
Table 2. Effect of a hypoxemia challenge on blood gas status, glucose concentration, BP, and HR

\begin{tabular}{|c|c|c|c|c|c|c|}
\hline \multirow[b]{2}{*}{ Sample } & \multicolumn{6}{|c|}{ Saline } \\
\hline & Pre-HX & $\mathrm{HX}$ & Post-HX & Pre-HX & $\mathrm{HX}$ & Post-HX \\
\hline $\mathrm{PaO}_{2}(\mathrm{~mm} \mathrm{Hg})$ & $23.2 \pm 1.46$ & $14.2 \pm 1.08 *$ & $22.0 \pm 1.17$ & $111.8 \pm 8.12$ & $50.7 \pm 4.72 *$ & $117.1 \pm 5.47$ \\
\hline $\mathrm{PaCO}_{2}(\mathrm{~mm} \mathrm{Hg})$ & $51.6 \pm 1.48$ & $48.7 \pm 1.52$ & $50.1 \pm 2.08$ & $39.6 \pm 1.67$ & $34.8 \pm 1.84$ & $38.9 \pm 1.95$ \\
\hline $\mathrm{O}_{2}$ sat $(\%)$ & $62.3 \pm 3.72$ & $32.4 \pm 5.66^{*}$ & $63.2 \pm 1.66$ & $94.5 \pm 0.81$ & $55.5 \pm 12.00^{*}$ & $95.2 \pm 0.42$ \\
\hline Glucose $(\mathrm{mmol} / \mathrm{L})$ & $1.0 \pm 0.14$ & $1.6 \pm 0.21 *$ & $1.0 \pm 0.25$ & $3.7 \pm 0.24$ & $3.6 \pm 0.20$ & $4.0 \pm 0.24$ \\
\hline $\mathrm{IG}(\mathrm{mmol} / \mathrm{L})$ & & $0.56 \pm 0.000$ & $0.00 \pm 0.000$ & & & \\
\hline $\mathrm{BP}(\mathrm{mm} \mathrm{Hg})$ & $40.1 \pm 2.53$ & $40.3 \pm 0.71$ & $41.9 \pm 0.40$ & $90.5 \pm 3.58$ & $89.6 \pm 4.37$ & $86.4 \pm 3.66$ \\
\hline \multirow[t]{2}{*}{ HR } & $187.3 \pm 9.96$ & $184.9 \pm 6.07$ & $186.3 \pm 10.21$ & $99.4 \pm 10.28$ & $100.2 \pm 6.58$ & $98.9 \pm 4.66$ \\
\hline & \multicolumn{6}{|c|}{ DM } \\
\hline $\mathrm{PaCO}_{2}(\mathrm{~mm} \mathrm{Hg})$ & $49.9 \pm 1.50$ & $46.6 \pm 1.98$ & $46.7 \pm 1.80$ & $36.9 \pm 2.83$ & $31.9 \pm 0.88$ & $35.0 \pm 2.29$ \\
\hline $\mathrm{O}_{2}$ sat $(\%)$ & $68.2 \pm 2.53$ & $40.0 \pm 3.53^{*}$ & $66.7 \pm 2.03$ & $95.2 \pm 1.06$ & $71.2 \pm 7.71 *$ & $95.6 \pm 0.72$ \\
\hline $\mathrm{Hb}(\mathrm{mg} / \mathrm{dL})$ & $8.7 \pm 0.76$ & $7.7 \pm 1.24$ & $8.6 \pm 0.41$ & $9.1 \pm 0.28$ & $9.6 \pm 0.45$ & $9.5 \pm 0.28$ \\
\hline Het $(\%)$ & $33.4 \pm 3.55$ & $29.5 \pm 2.19$ & $29.7 \pm 1.54$ & $29.3 \pm 1.62$ & $29.8 \pm 1.46$ & $28.2 \pm 2.17$ \\
\hline Glucose $(\mathrm{mmol} / \mathrm{L})$ & $1.5 \pm 0.10$ & $1.9 \pm 0.08 * \dagger$ & $2.1 \pm 0.17^{* \dagger}$ & $4.4 \pm 0.20 \dagger$ & $4.3 \pm 0.14 \dagger$ & $4.6 \pm 0.08 \dagger$ \\
\hline IG (mmol/L) & & $0.39 \pm 0.000 \dagger$ & $0.53 \pm 0.000 \dagger$ & & & \\
\hline $\mathrm{BP}$ (mm Hg) & $44.1 \pm 1.62$ & $48.0 \pm 2.75^{*} \dagger$ & $48.9 \pm 1.65 * \dagger$ & $95.0 \pm 9.02$ & $97.9 \pm 9.07$ & $92.5 \pm 7.89$ \\
\hline HR & $186.4 \pm 10.28$ & $183.6 \pm 5.58$ & $185.8 \pm 11.81$ & $94.6 \pm 10.34$ & $93.4 \pm 14.88$ & $97.7 \pm 10.78$ \\
\hline
\end{tabular}

IG, incremental increase in glucose concentration.

Data collected at 30 and 15 min before onset of hypoxemia (Pre-HX), 15 and 45 min after onset of hypoxemia (HX), and 15 min after the end of the hypoxemia (Post-HX) were averaged from mothers and fetuses at $105 \mathrm{dGA}$ that were treated with saline $(n=4)$ or DM $(n=6)$ for $48 \mathrm{~h}$ before hypoxemia. Mean \pm SEM.

$* p<0.05$ compared with Pre-HX.

$\dagger p<0.05$ compared with saline-treated controls.

period of DM, adrenal blood flow was reduced and adrenal vascular resistance was increased compared with salinetreated fetuses. Acute hypoxemia increased fetal adrenal blood flow in both treatment groups, but adrenal vascular resistance decreased only in saline-treated fetuses. In addi-
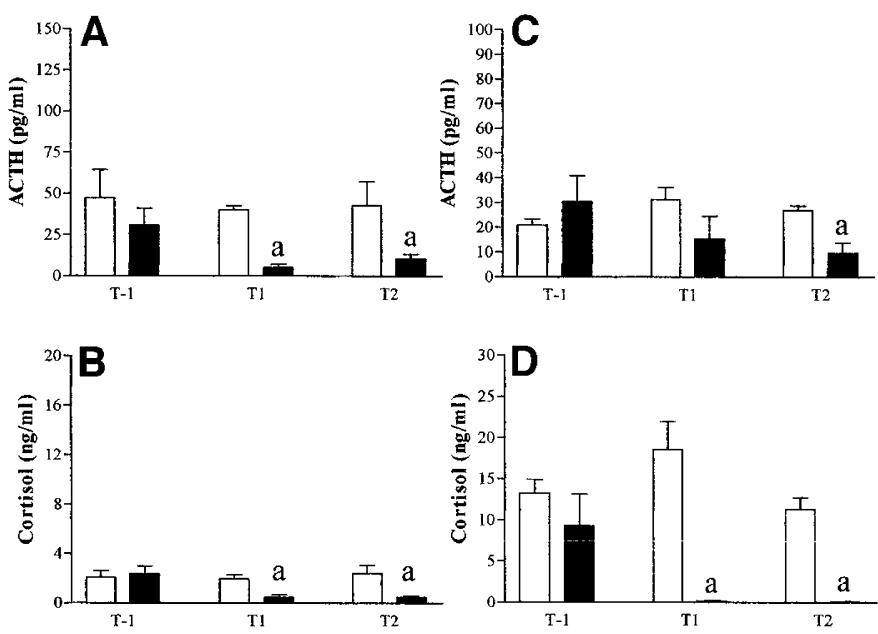

Figure 1. Fetal plasma ACTH $(A)$ and cortisol $(B)$ and maternal plasma ACTH $(C)$ and cortisol $(D)$ concentrations measured at baseline (T-1), after the first treatment day (T1) and after the second treatment day (T2) from pregnant ewes that were treated with saline $(\square ; n=4)$ or DM $(\square ; n=6)$ for $48 \mathrm{~h}$ beginning at $0900 \mathrm{~h}$ at $103 \mathrm{~d}$ of gestation. Mean \pm SEM; ${ }^{\mathrm{a}} p<0.05$ compared with baseline and saline-treated group. tion, cardiac blood flow increased in both treatment groups, in association with a decrease in cardiac vascular resistance during hypoxemia. Hypoxemia reduced fetal renal cortex blood flow in saline-treated animals but not in DM-treated
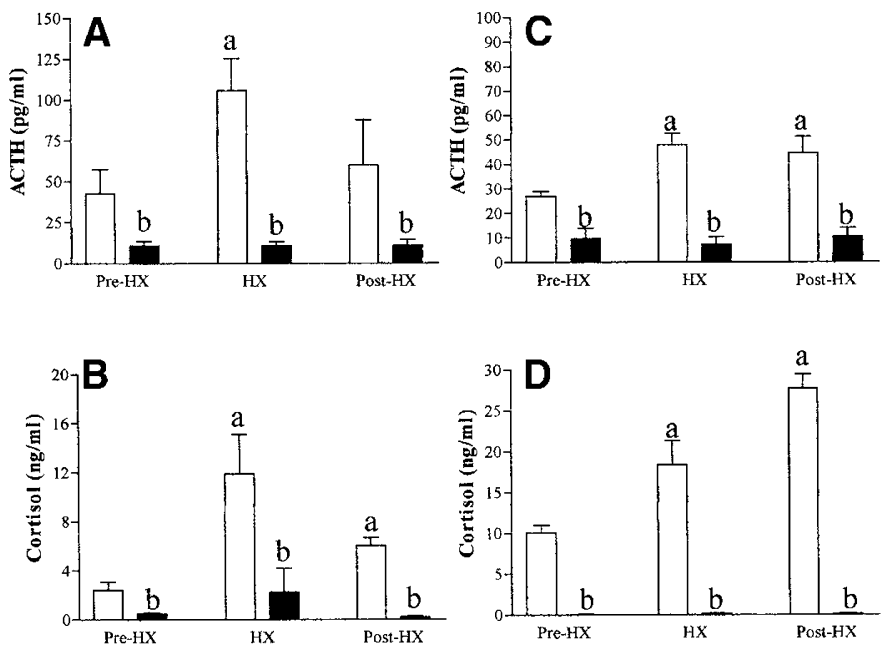

Figure 2. Fetal plasma $\mathrm{ACTH}(A)$ and cortisol $(B)$ and maternal plasma ACTH $(C)$ and cortisol $(D)$ concentrations measured 15-30 min before (Pre$\mathrm{HX}$ ), during (HX), and $15 \mathrm{~min}$ after (Post-HX) a 1-h hypoxemia challenge (decrease in fetal $\mathrm{PaO}_{2}$ by $40 \%$ ) from pregnant ewes at $105 \mathrm{dGA}$ that were treated with saline $(\square ; n=4)$ or DM $(\square ; n=6)$ for $48 \mathrm{~h}$ before the challenge. Mean \pm SEM; ${ }^{\mathrm{a}} p<0.05$ compared with Pre-HX, ${ }^{\mathrm{b}} p<0.05$ compared with saline-treated group. 

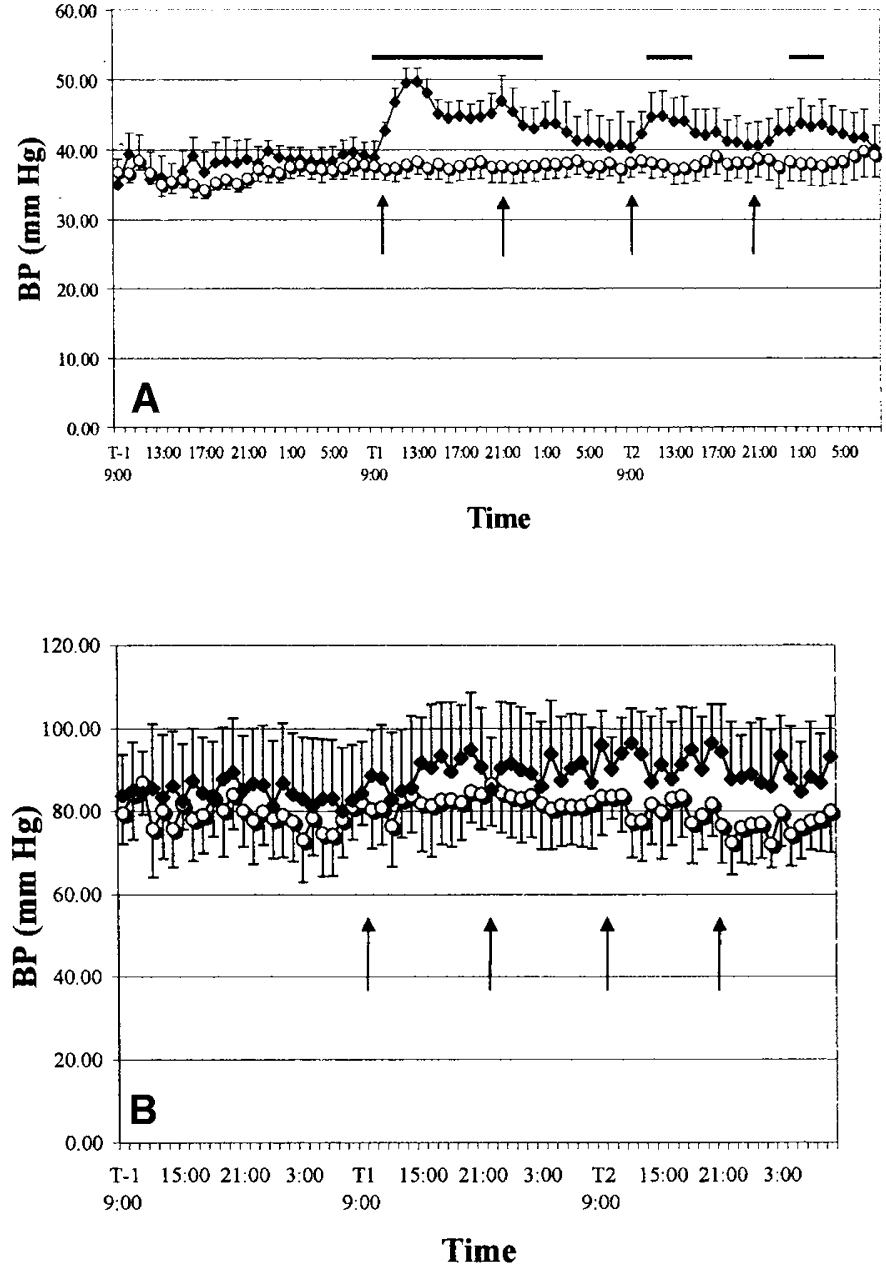

Figure 3. Fetal $(A)$ and maternal $(B)$ arterial BP measured from 102 dGA for a 24-h baseline period (T-1) and continued for $2 \mathrm{~d}$ during maternal saline $(O)$ or DM (- T1 and T2) treatment with arrows indicating the time of the injection. Mean \pm SEM; bars indicate time points when BP was different from saline group $(p<0.05)$.

fetuses. This change was due to an increase in vascular resistance in the saline-treated group. Hypoxemia reduced femoral blood flow in saline-treated animals, whereas femoral vascular resistance was increased in both treatment groups with a greater increase after DM treatment. In addition, hypoxemia increased cerebral cortical blood flow in DM-treated fetuses but not in the saline group, although cortical vascular resistance did not change significantly.

The effects of hypoxemia on maternal organ blood flow are also summarized in Figure 4. There were no DM-induced changes in organ blood flow before hypoxemia, but femoral vascular resistance was higher in the DM-treated ewes. Acute hypoxemia decreased renal cortex and femoral muscle blood flow in saline-treated mothers but not in the DM-treated mothers. Femoral vascular resistance increased in both treatment groups during hypoxemia. Neither glucocorticoid treatment nor hypoxemia significantly changed maternal adrenal cortical or medullary blood flow in both the saline and DM-treated groups.

\section{DISCUSSION}

Effects of DM treatment and hypoxemia on blood gas status. Fetal blood gas values at $105 \mathrm{dGA}$ presented here were similar to those reported in other studies in the last third of gestation $(24,25,31,35-37)$. DM treatment had no effect on fetal or maternal blood gas values. In addition, blood gas values from ewes at $105 \mathrm{dGA}$ were similar to what has been reported in ewes in the later stages of pregnancy $(31,37)$. During hypoxemia, the fall in neither $\mathrm{PaO}_{2}$ nor $\mathrm{O}_{2}$ sat was influenced by DM treatment. Previous studies have reported that acute fetal hypoxemia results in changes in blood gas values, such as a decreased $\mathrm{pH}$, increase in hematocrit, and increase or decrease in $\mathrm{Hb}$ concentration $(26,31,36-39)$. In this study, we found no significant changes in fetal or maternal arterial $\mathrm{pH}, \mathrm{PaCO}_{2}, \mathrm{Hb}$ concentration, or hematocrit during $1 \mathrm{~h}$ of reduced maternal inspired $\mathrm{O}_{2}$. This finding is in agreement with previous studies in saline-infused (40) and cortisolinfused fetuses (30).

Effects of DM treatment and hypoxemia on glucose concentration. As reported in older fetuses $(31,41)$, DM treatment produced a profound hyperglycemic response in both fetuses and pregnant ewes at 103-104 dGA. Glucocorticoid administration increases hepatic glycogen content (42) and hepatic and renal gluconeogenic enzyme activities (43). Our observations therefore suggest a glucocorticoid-accelerated maturation of fetal glucose mobilization.

Acute hypoxemia increased fetal glucose concentrations, which remained higher in DM-treated fetuses compared with control fetuses during and after the hypoxemia challenge. In the only other study published on the effects of hypoxia on glucose concentrations at this stage of gestation, fetal hyperglycemia did not occur (44). However, our findings are in agreement with research in older fetuses $(>124 \mathrm{dGA})$ that were either infused with DM for $48 \mathrm{~h}$ (31) or had endogenously elevated cortisol concentrations (36), in which hypoxia produced higher glucose concentrations compared with controls. Changes in fetal plasma glucose in response to acute hypoxia are probably the result of catecholamine responses (45). In saline-treated ewes, we found that acute hypoxemia did not increase maternal glucose concentrations. However, similar to the observations in the fetuses, DM-treated mothers had elevated glucose concentrations at all time points of the hypoxemia challenge compared with controls.

Effects of DM treatment and hypoxemia on ACTH and cortisol concentrations. Our finding that maternal DM treatment at $105 \mathrm{dGA}$ significantly reduced fetal cortisol and ACTH levels differs from previous studies in which fetal DM infusion had little effect on basal plasma ACTH and cortisol concentrations in fetuses $>120 \mathrm{dGA}(22,31,46)$. These findings are in keeping with the concept that the sensitivity of the hypothalamic-pituitary-adrenal system to negative feedback is greater earlier in gestation and disappears, thereby allowing the endogenous rise in cortisol that usually occurs at $\sim 125 \mathrm{dGA}(6$, 47). We also found that maternal DM treatment reduced maternal cortisol and ACTH levels. It took an additional $24 \mathrm{~h}$ of DM treatment to decrease maternal ACTH compared with fetal levels, suggesting increased fetal pituitary sensitivity to the 

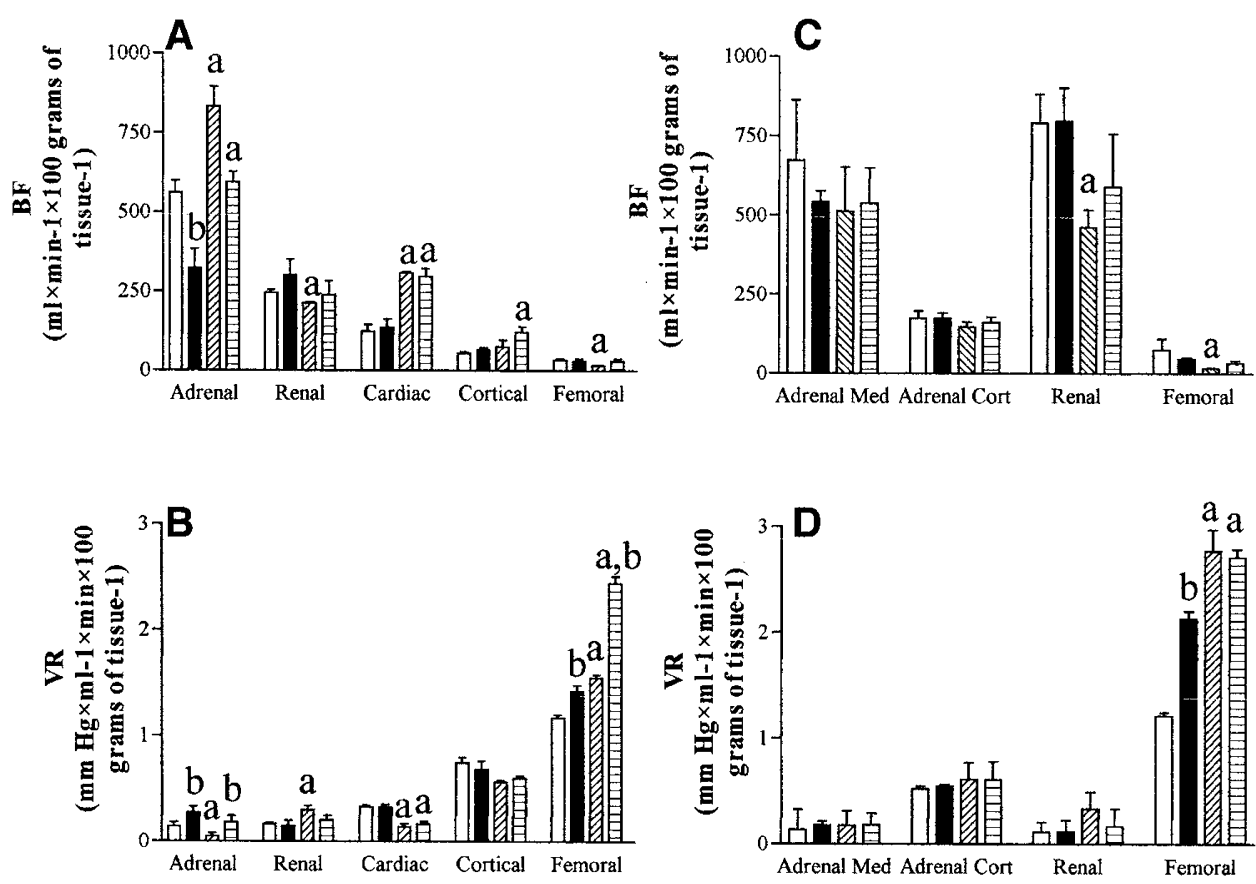

Figure 4. Fetal organ blood flow (BF; $A)$ and vascular resistance $(\mathrm{VR} ; B)$ and maternal organ $\mathrm{BF}(C)$ and VR $(D)$ measured at 10 min before $($ Pre-HX) and 50 min into (HX) a hypoxemia challenge from fetuses at $105 \mathrm{dGA}$ after maternal treatment with either DM or saline. Pre-HX saline ( $\square$; $n=4)$, Pre-HX DM $(\square ; n=6)$, HX saline ( $\mathbb{\mathbb { Q }} ; n=4)$, HX DM (目; $n=6)$. Mean \pm SEM; ${ }^{\mathrm{a}} p<0.05$ compared with Pre-HX; ${ }^{\mathrm{b}} p<0.05$ compared with saline-treated group.

negative feedback of glucocorticoids compared with the adult. The significant decrease in maternal cortisol in response to DM in the absence of a fall in maternal ACTH suggests an action of DM at the adrenal level in the adult.

The magnitude of fetal pituitary-adrenal responses to acute hypoxemia in the saline-treated group were greater than those reported previously for fetuses at later gestational ages $(>120$ dGA), although the baseline values were less $(22,25,31,37$, 48,49 ). In our study, we found that fetal cortisol concentrations at baseline were $\sim 3 \mathrm{ng} / \mathrm{mL}$ and quadrupled to $\sim 12 \mathrm{ng} / \mathrm{mL}$ during hypoxemia. Others have reported that between 127 and $130 \mathrm{dGA}$, baseline fetal cortisol concentrations range from $\sim 12$ to $20 \mathrm{ng} / \mathrm{mL}$, which more than doubled to $\sim 29-55 \mathrm{ng} / \mathrm{mL}$ during hypoxemia $(25,37)$. In the present study, fetal cortisol remained significantly elevated for $15 \mathrm{~min}$ after return to a normoxic condition, similar to a previous report in which umbilical cord compression increased endogenous fetal cortisol concentration (37). Saline-treated ewes responded to acute hypoxemia similarly to their fetuses, except that both cortisol and ACTH concentrations remained elevated $15 \mathrm{~min}$ after ending the hypoxemia challenge. One previous study in which maternal $\mathrm{PaO}_{2}$ was reduced to $57 \mathrm{~mm} \mathrm{Hg}$ did not observe the maternal pituitary-adrenal response seen here to a maternal $\mathrm{PaO}_{2}$ of $50 \mathrm{~mm} \mathrm{Hg} \mathrm{(24).}$

Effects of DM treatment and hypoxemia on cardiovascular responses. Administration of $12 \mathrm{mg}$ of DM i.m. to ewes at 127-133 dGA is followed by fetal hypertension with fetal BP returning to normal within $12 \mathrm{~h}$ (19). In this study, we found that maternal DM treatment resulted in fetal hypertension that was short-lived and diminished with subsequent injections. We have investigated the peripheral mechanisms by which glucocorticoids increase BP and have demonstrated an increase in vasoconstriction of small resistance arteries in the fetal sheep in response to endothelin as the fetus matures during the final third of gestation (50), which is mimicked by administration of DM directly to the fetus (51). However, in the adult rat, the pressor effects of ACTH are not ameliorated by endothelin-1 antagonism with bosetan (52). Unlike the actions of mineralocorticoids, glucocorticoid-induced hypertension is not mediated by increased sympathetic tone (53) and in humans is associated with either normal or decreased sympathetic activity (54). In keeping with evidence in humans that suppression of the nitric oxide system may play a role in cortisol-induced hypertension (55-58), we have demonstrated impairment of fetal femoral artery nitric oxide production after three courses of DM administration to the ewe (59).

Fetal hypoxemia has been demonstrated to produce hypertension in fetal sheep $>120$ dGA $(35,60,61)$. Severe maternal hypoxemia induced by apnea has been demonstrated to produce hypertension in nonpregnant ewes (62). In the current study, neither the saline-treated fetuses nor mothers became hypertensive. Akagi et al. (30) also demonstrated that maternal and fetal hypoxemia could be induced in sheep at 125 dGA by reducing maternal inspired $\mathrm{O}_{2}$ content without inducing hypertension. Several studies have shown that late in gestation, fetal hypoxemia does elevate fetal blood pressure $(23,24,26,27$, 36 ). In our study, hypertension supervened after hypoxemia in the DM-treated but not control fetuses at $105 \mathrm{dGA}$, producing the response characteristic of a more mature fetus. This altered response indicates a premature expression of vascular changes that do not normally occur until a later stage of development.

Effects of DM treatment and hypoxemia on organ blood flow. Fetal adrenal blood flow has been shown to be very sensitive to circulating $\mathrm{ACTH}$, and it therefore is not surprising 
that fetal adrenal flow fell and vascular resistance increased after DM (63). In contrast, maternal adrenal flow does not seem to be dependent on $\mathrm{ACTH}$ concentrations because it was not altered when maternal ACTH fell. DM increased the vascular resistance in the femoral bed in both mother and fetus, again demonstrating the importance of the carcass as a reservoir of peripheral resistance. The major effect of hypoxemia was to further increase vascular resistance in the maternal and fetal femoral vascular beds and decrease fetal cardiac vascular resistance in both groups. DM enhanced the hypoxemiainduced peripheral vasoconstriction, increasing the fetal femoral vascular resistance by $72 \%$ as compared with the salinetreated group, in which it increased by $32 \%$. We previously demonstrated that betamethasone given directly to the fetus at 125 dGA decreases fetal cerebral blood flow and blunts hypercapnia-induced vasodilation (15). In contrast, maternal administration at this earlier gestational age seems to provide a slight increase in cortical flow.

In summary, we have reported on the maternal and fetal adrenal responses to hypoxemia after maternally administered $\mathrm{DM}$ at 0.7 of gestation. Similar to later in gestation, maternal glucocorticoid administration results in fetal and maternal hyperglycemia as well as cortisol and ACTH suppression. Ewes remained normotensive, whereas fetuses became hypertensive. DM alters fetal responses to hypoxemia in a manner that resembles the changes that occur later in gestation.

Acknowledgments. We thank Susan Jenkins for data analysis and Jill McDonald for technical support.

\section{REFERENCES}

1. National Institutes of Health Consensus Development Conference 2000 Antenatal corticosteroids revisited: repeat courses. NIH Consens Statement 17:1-18

2. National Institutes of Health Consensus Development Conference 1994 Effect of corticosteroids for fetal maturation on perinatal outcomes. NIH Consens Statement 12:1-24

3. Clarke KA, Ward JW, Forhead AJ, Giussani DA, Fowden AL 2002 Regulation of 11 beta-hydroxysteroid dehydrogenase type 2 activity in ovine placenta by fetal cortisol. J Endocrinol 172:527-534

4. Forhead AJ, Fowden AL 2002 Effects of thyroid hormones on pulmonary and renal angiotensin-converting enzyme concentrations in fetal sheep near term. J Endocrinol 173:143-150

5. Fencl M, Stillman RJ, Cohen J, Tulchinsky D 1980 Direct evidence of sudden rise in fetal corticoids late in human gestation. Nature 287:225-226

6. Magyar DM, Fridshal D, Elsner CW, Glatz T, Eliot J, Klein AH, Lowe KC, Buster JE, Nathanielsz PW 1980 Time-trend analysis of plasma cortisol concentrations in the fetal sheep in relation to parturition. Endocrinology 107:155-159

7. Walfisch A, Hallak M, Mazor M 2001 Multiple courses of antenatal steroids: risks and benefits. Obstet Gynecol 98:491-497

8. Crowley PA 2000 Prophylactic corticosteroids for preterm birth. Cochrane Database Syst Rev (2):CD000065

9. Merrill JD, Ballard RA 2000 Clinical use of antenatal corticosteroids: benefits and risks. Pediatr Rev 1:E91-E98

10. Smith LM, Qureshi N, Chao CR 2000 Effects of single and multiple courses of antenatal glucocorticoids in preterm newborns less than 30 weeks' gestation. J Matern Fetal Med 9:131-135

11. Rehan VK 1996 Antenatal steroids: miracle drug for preemies. Indian J Pediatr 63:599-608

12. Crowley PA 1995 Antenatal corticosteroid therapy: a meta-analysis of the randomized trials, 1972 to 1994. Am J Obstet Gynecol 173:322-335

13. French NP, Hagan R, Evans SF, Godfrey M, Newnham JP 1999 Repeated antenatal corticosteroids: size at birth and subsequent development. Am J Obstet Gynecol 180:114-121

14. Reinisch JM, Simon NG, Karow WG, Gandelman R 1978 Prenatal exposure to prednisone in humans and animals retards intrauterine growth. Science 202:436-438

15. Schwab M, Roedel M, Anwar MA, Muller T, Schubert H, Buchwalder LF, Walter B, Nathanielsz PW 2000 Effects of betamethasone administration to the fetal sheep in late gestation on fetal cerebral blood flow. J Physiol 528:619-632

16. Smith LM, Ervin MG, Wada N, Ikegami M, Polk DH, Jobe AH 2000 Antenatal glucocorticoids alter postnatal preterm lamb renal and cardiovascular responses to intravascular volume expansion. Pediatr Res 47:622-627
17. Anwar MA, Schwab M, Poston L, Nathanielsz PW 1999 Betamethasone-mediated vascular dysfunction and changes in hematological profile in the ovine fetus. Am J Physiol 276:H1137-H1143

18. Derks JB, Giussani DA, Jenkins SL, Wentworth RA, Visser GHA, Padbury JF, Nathanielsz PW 1997 A comparative study of cardiovascular, endocrine and behavioural effects of betamethasone and dexamethasone administration to fetal sheep. J Physiol 499:217-226

19. Bennet L, Kozuma S, McGarrigle HH, Hanson MA 1999 Temporal changes in fetal cardiovascular, behavioural, metabolic and endocrine responses to maternally administered dexamethasone in the late gestation fetal sheep. Br J Obstet Gynecol 106:331339

20. Ervin MG, Padbury JF, Polk DH, Ikegami M, Berry LM, Jobe AH 2000 Antenatal glucocorticoids alter premature newborn lamb neuroendocrine and endocrine responses to hypoxia. Am J Physiol Regul Integr Comp 279:R830-R838

21. Matthews SG 2000 Antenatal glucocorticoids and programming of the developing CNS. Pediatr Res 47:291-300

22. Giussani DA, McGarrigle HH, Moore PJ, Bennet L, Spencer JAD, Hanson MA 1994 Carotid sinus nerve section and the increase in plasma cortisol during acute hypoxia in fetal sheep. J Physiol 477:75-80

23. Giussani DA, Spencer JA, Moore PJ, Bennet L, Hanson MA 1993 Afferent and efferent components of the cardiovascular reflex responses to acute hypoxia in term fetal sheep. J Physiol 461:431-449

24. Akagi K, Challis JR 1990 Hormonal and biophysical responses to acute hypoxemia in fetal sheep at 0.7-0.8 gestation. Can J Physiol Pharmacol 68:1527-1532

25. Akagi K, Challis JR 1990 Relationship between blood gas values and hormonal response to acute hypoxemia in fetal sheep. Gynecol Obstet Invest 30:65-70

26. Iwamoto HS, Kaufman T, Keil LC, Rudolph AM 1989 Responses to acute hypoxemia in fetal sheep at 0.6-0.7 gestation. Am J Physiol 256:H613-H620

27. Walker AM, Cannata JP, Dowling MH, Ritchie BC, Maloney JE 1979 Age-dependent pattern of autonomic heart rate control during hypoxia in fetal and newborn lambs. Biol Neonate 35:198-208

28. Rudolph AM, Heymann MA 1970 Circulatory changes during growth in the fetal lamb. Circ Res 26:289-299

29. Brooks AN, Currie IS, Gibson F, Thomas GB 1992 Neuroendocrine regulation of sheep fetuses. J Reprod Fertil Suppl 45:69-84

30. Akagi K, Berdusco ET, Challis JR 1990 Cortisol inhibits ACTH but not the AVP response to hypoxemia in fetal lambs at days 123-128 of gestation. J Dev Physiol $14: 319-324$

31. Fletcher AJ, Goodfellow MR, Forhead AJ, Gardner DS, McGarrigle HH, Fowden AL, Giussani DA 2000 Low doses of dexamethasone suppress pituitary-adrenal function but augment the glycemic response to acute hypoxemia in fetal sheep during late gestation. Pediatr Res 47:684-691

32. McDonald TJ, Hoffmann GE, Myers DA, Nathanielsz PW 1990 Hypothalamic glucocorticoid implants prevent fetal ovine adrenocorticotropin secretion in response to stress. Endocrinology 127:2862-2868

33. Gleed RD, Poore ER, Figueroa JP, Nathanielsz PW 1986 Modification of maternal and fetal oxygenation with the use of tracheal gas infusion. Am J Obstet Gynecol $155: 429-435$

34. Buchwalder LF, Lin M, McDonald TJ, Nathanielsz PW 1998 Fetal sheep adrenal blood flow responses to hypoxemia after splanchnicotomy using fluorescent microspheres. J Appl Physiol 84:82-89

35. Harris AP, Helou S, Gleason CA, Traystman RJ, Koehler RC 2001 Fetal cerebral and peripheral circulatory responses to hypoxia after nitric oxide synthase inhibition. Am J Physiol Regul Integr Comp 281:R381-R390

36. Gardner DS, Fletcher AJ, Bloomfield MR, Fowden AL, Giussani DA 2002 Effects of prevailing hypoxaemia, acidaemia or hypoglycaemia upon the cardiovascular, endocrine and metabolic responses to acute hypoxaemia in the ovine fetus. J Physiol 540:351-366

37. Gardner DS, Fletcher AJW, Fowden AL, Giussani DA 2001 Plasma adrenocorticotropin and cortisol concentrations during acute hypoxemia after a reversible period of adverse intrauterine conditions in the ovine fetus during late gestation. Endocrinology 142:589-598

38. Green LR, McGarrigle HH, Bennet L, Hanson MA 1998 Angiotensin II and cardiovascular chemoreflex responses to acute hypoxia in late gestation fetal sheep. J Physiol 507:857-867

39. Steyn C, Hanson MA 1998 The effect of repeated acute hypoxemia on fetal cardiovascular development in the sheep. J Physiol 512:295-306

40. Woudstra BR, Aarnoudse JG, de Wolf BT, Zijlstra WG 1990 Nuchal muscle activity at different levels of hypoxemia in fetal sheep. Am J Obstet Gynecol 162.559-564

41. Barbera A, Wilkening RB, Teng C, Battaglia FC, Meschia G 1997 Metabolic alterations in the fetal hepatic and umbilical circulations during glucocorticoidinduced parturition in sheep. Pediatr Res 41:242-248

42. Barnes RJ, Comline RS, Silver M 1978 Effect of cortisol on liver glycogen concentrations in hypophysectomized, adrenalectomized and normal fetal lambs during late or prolonged gestation. J Physiol 275:567-579

43. Fowden AL, Mijovic J, Silver M 1993 The effects of cortisol on hepatic and renal gluconeogenic enzyme activities in the sheep fetus during late gestation. J Endocrinol $137: 213-222$

44. Jones CT 1977 The development of some metabolic responses to hypoxia in the fetal sheep. J Physiol 265:743-762

45. Hooper SB 1995 Fetal metabolic responses to hypoxia. Reprod Fertil Dev 7:527-538

46. Fowden AL, Li J, Forhead AJ 1998 Glucocorticoids and the preparation for life after birth: are there long-term consequences of the life insurance? Proc Nutr Soc 57:113122

47. Wood CE 1987 Does a decrease in cortisol negative feedback efficacy precede ovine parturition? Am J Physiol 252:R624-R627 
48. Towell ME, Figueroa J, Markowitz S, Elias B, Nathanielsz PW 1987 The effect of mild hypoxemia maintained for twenty-four hours on maternal and fetal glucose, lactate, cortisol, and arginine vasopressin in pregnant sheep at 122 to 139 days' gestation. Am J Obstet Gynecol 157:1550-1557

49. Boddy K, Jones CT, Mantell C, Ratcliffe JG, Robinson JS 1974 Changes in plasma $\mathrm{ACTH}$ and corticosteroid of the maternal and fetal sheep during hypoxia. Endocrinology 94:588-591

50. Docherty CC, Kalmar-Nagy J, Engelen M, Nathanielsz PW 2001 Development of fetal vascular responses to endothelin-1 and acetylcholine in the sheep. Am J Physiol 280:R554-R562

51. Docherty CC, Kalmar-Nagy J, Engelen M, Koenen SV, Nijland M, Kuc RE, Davenport AP, Nathanielsz PW 2001 Effect of in vivo fetal infusion of dexamethasone at $0.75 \mathrm{GA}$ on fetal ovine resistance artery responses to ET-1. Am J Physiol 281:R261-R268

52. Fraser TB, Mangos GJ, Turner SW, Whitworth JA 1999 Adrenocorticotrophic hormone-induced hypertension in the rat: effects of the endothelin antagonist bosentan. Clin Exp Pharmacol Physiol 26:628-633

53. Whitworth JA, Schyvens CG, Zhang Y, Mangos GJ, Kelly JJ 2001 Glucocorticoidinduced hypertension: from mouse to man. Clin Exp Pharmacol Physiol 28:993-996

54. Sudhir K, Jennings GL, Esler MD, Korner PI, Blombery PA, Lambert GW, Scoggins B, Whitworth JA 1989 Hydrocortisone-induced hypertension in humans: presso responsiveness and sympathetic function. Hypertension 13:416-421
55. Kelly JJ, Williamson P, Martin A, Whitworth JA 2001 Effects of oral L-arginine on plasma nitrate and blood pressure in cortisol-treated humans. J Hypertens 19:263-268

56. Mangos GJ, Turner SW, Fraser TB, Whitworth JA 2000 The role of corticosterone in corticotrophin (ACTH)-induced hypertension in the rat. J Hypertens 18:1849-1855

57. Kelly JJ, Mangos G, Williamson PM, Whitworth JA 1998 Cortisol and hypertension. Clin Exp Pharmacol Physiol Suppl 25:S51-S56

58. Kelly JJ, Tam SH, Williamson PM, Lawson J, Whitworth JA 1998 The nitric oxide system and cortisol-induced hypertension in humans. Clin Exp Pharmacol Physiol 25:945-946

59. Molnar J, Nijland MJ, Howe DC, Nathanielsz PW 2002 Evidence for microvascular dysfunction after prenatal dexamethasone exposure at $0.7,0.75$ and 0.8 gestation in sheep. Am J Physiol 283:R561-R567

60. Giussani DA, Gardner DS, Cox DT, Fletcher AJ 2001 Purinergic contribution to circulatory, metabolic, and adrenergic responses to acute hypoxemia in fetal sheep. Am J Physiol 280:R678-R685

61. LaGamma EF, Itskovitz J, Rudolph AM 1982 Effects of naloxone on fetal circulatory responses to hypoxemia. Am J Obstet Gynecol 143:933-940

62. Greiss Jr FC, Anderson SG, King LC 1972 Uterine vascular bed: effects of acute hypoxia. Am J Obstet Gynecol 113:1057-1064

63. Carter AM, Richardson BS, Homan J, Towstoless M, Challis JR 1993 Regional adrenal blood flow responses to adrenocorticotropic hormone in fetal sheep. Am J Physiol 264:E264-E269 